\title{
Wounding of Arabidopsis halleri leaves enhances cadmium accumulation that acts as a defense against herbivory
}

\author{
Sonia Plaza · Johann Weber · Simone Pajonk · Jérôme Thomas • Ina N. Talke • \\ Maja Schellenberg $\cdot$ Sylvain Pradervand $\cdot$ Bo Burla $\cdot$ Markus Geisler • \\ Enrico Martinoia $\cdot$ Ute Krämer
}

Received: 7 January 2015/ Accepted: 1 February 2015/Published online: 10 March 2015

(C) The Author(s) 2015. This article is published with open access at Springerlink.com

\begin{abstract}
Approximately $0.2 \%$ of all angiosperms are classified as metal hyperaccumulators based on their extraordinarily high leaf metal contents, for example $>1 \%$ zinc, $>0.1 \%$ nickel or $>0.01 \%$ cadmium (Cd) in dry biomass. So far, metal hyperaccumulation has been considered to be a taxon-wide, constitutively expressed trait, the extent of which depends solely on available metal concentrations in the soil. Here we show that in the facultative metallophyte Arabidopsis halleri, both insect herbivory and mechanical wounding of leaves trigger an increase specifically in leaf $\mathrm{Cd}$ accumulation.
\end{abstract}

Sonia Plaza and Johann Weber have contributed equally to the work.

Electronic supplementary material The online version of this article (doi:10.1007/s10534-015-9829-9) contains supplementary material, which is available to authorized users.

S. Plaza · M. Schellenberg · B. Burla .

M. Geisler · E. Martinoia ( $\square)$

Institute of Plant Biology, University of Zurich,

8008 Zurich, Switzerland

e-mail: enrico.martinoia@botinst.uzh.ch

Present Address:

S. Plaza

Institute of Plant Sciences, University of Bern, 3013 Bern,

Switzerland

J. Weber $\cdot$ J. Thomas $\cdot$ S. Pradervand

Center for Integrative Genomics, University of Lausanne,

1015 Lausanne, Switzerland
Moreover, the $\mathrm{Cd}$ concentrations accumulated in leaves can serve as an elemental defense against herbivory by larvae of the Brassicaceae specialist small white (Pieris rapae), thus allowing the plant to take advantage of this non-essential trace element and toxin. Metal homeostasis genes are overrepresented in the systemic transcriptional response of roots to the wounding of leaves in A. halleri, supporting that leaf $\mathrm{Cd}$ accumulation is preceded by systemic signaling events. A similar, but quantitatively less pronounced transcriptional response was observed in A. thaliana, suggesting that the systemically regulated modulation of metal homeostasis in response to leaf wounding also occurs in non-hyperaccumulator plants. This is the first report of an environmental stimulus influencing metal hyperaccumulation.

\author{
S. Pajonk · I. N. Talke - U. Krämer $(\square)$ \\ Department of Plant Physiology, Ruhr University \\ Bochum, Universitaetsstrasse 150 ND3/30, \\ 44801 Bochum, Germany \\ e-mail: ute.kraemer@ruhr-uni-bochum.de \\ Present Address: \\ I. N. Talke \\ Max Planck Institute of Molecular Plant Physiology, \\ 14476 Potsdam, Germany
}


Keywords Cadmium $(\mathrm{Cd}) \cdot$ Metal

hyperaccumulator plant $\cdot$ Iron $(\mathrm{Fe}) \cdot$ Jasmonate $\cdot$ Insect herbivory $\cdot$ Pieris rapae $\cdot$ Chemical ecology

Elemental defence $\cdot$ Phytoremediation

\section{Introduction}

The essential micronutrients zinc and nickel, as well as the non-essential metal cadmium $(\mathrm{Cd})$, can act as potent toxins when present in excess, endangering environmental and human health (Clemens et al. 2013). Within the characteristic vegetation shaped by high selection pressures occurring on heavy-metal rich soils, a small proportion of metallophyte plantsestimated to constitute around $1 \%$-accumulate extraordinarily high leaf metal concentrations (Baker and Brooks 1989). These rare metal hyperaccumulator plants are of considerable interest for the development of phytoremediation and phytomining technologies. To date, metal hyperaccumulation has been considered to be a constitutive trait, which is expressed taxon-wide under all conditions as long as bioavailable metal concentrations are sufficient in the soil. There is some evidence that the ecological role of metal hyperaccumulation in plants is to act as an elemental defense against pathogen attack and insect herbivory (Boyd 2007; Boyd and Martens 1992).

In the Brassicaceae family of flowering plants, Arabidopsis halleri is a well-known $\mathrm{Zn}$ hyperaccumulator that also exhibits hypertolerance to both $\mathrm{Zn}$ and Cd (Verbruggen et al. 2009). Moreover, A. halleri individuals collected from one natural population have been reported to contain hyperaccumulator concentrations of Cd exceeding $100 \mu \mathrm{g} \mathrm{g}^{-1}$ in leaf dry biomass (Dahmani-Muller et al. 2000), but Cd hyperaccumulation appeared not to be a species-wide trait (Krämer 2010). As a member of the taxonomic sister group and

Present Address:

B. Burla

University Hospital Zurich, University of Zurich, 8006 Zurich, Switzerland

Present Address:

M. Geisler

Department of Biology, University of Fribourg, 1700 Fribourg, Switzerland very close relative of the genetic model plant $A$. thaliana, A. halleri is gaining increasing attention in comparative genomics studies addressing the molecular basis of metal hyperaccumulation and hypertolerance (Krämer 2010; Verbruggen et al. 2009). Alongside genetic approaches, these studies identified candidate genes, which were then functionally characterized. The stable genetic transformation-so far uniquely used in A. halleri among all metal hyperaccumulator taxa-has proven invaluable in demonstrating the biological functions of candidate genes (Hanikenne et al. 2008).

Using transgenic A. halleri Heavy Metal APTase4 (HMA4) RNA interference lines (Hanikenne et al. 2008), which are impeded in both $\mathrm{Zn}$ and $\mathrm{Cd}$ accumulation, Kazemi-Dinan et al. (2014) conducted a stringent test of the elemental defense hypothesis. Both wild-type and transgenic non-accumulating lines were grown under identical conditions prior to pairedchoice experiments using the specialist chewing herbivorous insects Athalia rosae and Phaedon cochleariae. In these assays, herbivores exhibited preferred feeding on non-accumulating transgenic lines by comparison to the hyperaccumulating wild type, in agreement with the elemental defense hypothesis (Kazemi-Dinan et al. 2014).

In plants, leaf wounding through insect herbivory is well known to induce the biosynthesis of secondary metabolites which act as defenses against herbivory (Mithofer and Boland 2012). Among these defense compounds, constitutive and herbivory-inducible production of glucosinolates, for example, is characteristic of the Brassicaceae including also A. halleri. Research testing the elemental defense hypothesis has not so far examined whether biotic stress has an effect on the extent of metal accumulation in hyperaccumulator plants. Here we show that herbivory by larvae of the small white butterfly Pieris rapae, and mechanical wounding simulating herbivory, both enhance $\mathrm{Cd}$ accumulation in leaves of $A$. halleri. We demonstrate that the accumulated levels of $\mathrm{Cd}$ deter feeding by Pieris rapae. The analysis of the wounding-induced systemic transcriptome in roots suggests a pronounced remodeling of metal homeostasis in response to wounding, which is also occurring-to a lesser extent-in A. thaliana. Our data show that $\mathrm{Cd}$ hyperaccumulation is inducible in A. halleri. This has profound consequences for future field and laboratory studies of hyperaccumulator plants. 
Moreover, our results suggest that future work should address the roles of transition metals in defense responses of A. thaliana.

\section{Methods}

Plant growth and wounding

Hydroponically grown (Massonneau et al. 2001) 9-week-old Arabidopsis halleri (accession Langelsheim, N51 $\left.56^{\prime} 35.2^{\prime \prime}, \mathrm{E} 10^{\circ} 20^{\prime} 56.3^{\prime \prime}\right)$ and $A$. thaliana (where appropriate) were transferred into a medium supplemented with $0.5 \mu \mathrm{M} \mathrm{CdCl}_{2}$ for 5 days before the initiation of wounding by herbivory through Pieris rapae larvae for $24 \mathrm{~h}$, or mechanical wounding carried out with a razor blade on a single leaf simulating extent and shape of herbivory by $P$. rapae. Roots were harvested for transcript profiling $5 \mathrm{~h}$ after mechanical leaf wounding, or the remaining intact leaves were harvested $72 \mathrm{~h}$ after the initiation of wounding for the quantification of Cd concentrations by AAS (Bovet et al. 2003). Leaf biomass eaten was quantified according to leaf surface areas scanned before and after feeding of an insect for $3 \mathrm{~h}$ on detached leaves from plants exposed to $0.5 \mu \mathrm{M} \mathrm{CdCl}_{2}$ or no Cd (controls) for 5 days (Leica IM1000 software). Seven-month-old A. halleri cultivated in pots $(60 \mathrm{~mm} \varnothing)$ of a 1:1 (v/v) mixture of vermiculite and an autoclaved, sieved $(5 \mathrm{~mm})$ metalcontaminated native soil (Langelsheim; exchangeable Cd $13.3 \mathrm{mg} \mathrm{kg}^{-1}$ ) were mechanically wounded simulating herbivory four times at 72-h intervals. For each wounding event, an undamaged leaf was perforated multiple times with a $1-\mathrm{mL}$ plastic pipette tip by pressing against a fragment of a lid of a plastic petri dish. Whole shoots were harvested $72 \mathrm{~h}$ after the fourth wounding event and rinsed in ultrapure water. Damaged leaves and leaves that had been in direct physical contact with the soil were removed from each plant. The remaining portion of each plant was dried and aciddigested before element analysis by ICP-OES (Becher et al. 2004). Statistics were done using SPSS 13. For the determination of exchangeable concentrations of elements in soil, $1 \mathrm{~g}$ soil, air-dried and sieved through a 2-mm mesh, was mixed with $10 \mathrm{~mL} 1 \mathrm{M}$ ammonium acetate, $\mathrm{pH} 7.0$, in a 15-mL screw-capped polypropylene tube, then shaken horizontally overnight at $150 \mathrm{rpm}$ at room temperature, followed by filtering through Whatman paper no. 1. Before analysis by ICP-
OES, $1 \mathrm{~mL}$ of $65 \%$ nitric acid was added to each sample.

RNA extraction and microarrays

Total root RNA was extracted with the RNeasy midi kit (Qiagen); mRNA was amplified with the MessageAmp aRNA II kit (Ambion). Five $\mu \mathrm{g}$ of aRNA were reverse transcribed into cyanin3- or cyanin5-labeled cDNA, and hybridized onto microarrays (GEO accession number GPL6147) containing 25,000 gene-specific tags for the A. thaliana genome (Hilson et al. 2004). Within-species changes in transcript levels between control and wounded plants were analyzed by two color co-hybridization of the labeled cDNAs. After print tip lowess normalization (Yang et al. 2002) of raw data and statistical data analysis with the LIMMA package (http://www.bioconductor.org/), genes with an expression fold change $\geq 1.5$ and a $P$ value $<0.05$ (moderate $t$ statistics, four biological replicates) were considered as significantly differentially expressed between non-wounded control and wounded plants. Among regulated genes, an overrepresentation of metal homeostasis genes (Talke et al. 2006), genes upregulated under iron deficiency in roots (Colangelo and Guerinot 2004), and genes regulated by 12 -oxophytodienoic acid (OPDA) (Taki et al. 2005), cold, drought and UV-B (abiotic stress) (Kilian et al. 2007), herbivory (Reymond et al. 2004), methyl jasmonate (Nemhauser et al. 2006) or $\mathrm{NaCl}$ (Gong et al. 2005) was assessed using Fisher's exact test.

\section{Results}

To investigate the relationship between insect herbivory and $\mathrm{Cd}$ accumulation in A. halleri, larvae of Pieris rapae were allowed to feed for $24 \mathrm{~h}$ on 9-week-old $A$. halleri and $A$. thaliana plants, 5 days after the addition of a non-toxic concentration of $0.5 \mu \mathrm{M} \mathrm{Cd}$ to the hydroponic plant growth medium. $72 \mathrm{~h}$ after the initiation of feeding, intact leaves of $A$. halleri subjected to herbivory contained 1.97 - to 3.72 -fold higher $\mathrm{Cd}$ concentrations than leaves of non-wounded control plants (Fig. 1a; $P=0.02$ ). By contrast, we did not observe significant effects of wounding on leaf concentrations of $\mathrm{Zn}$ or other metals, and herbivory had no effect on leaf $\mathrm{Cd}$ concentrations in A. thaliana (not shown). Mimicking herbivory by removing $50 \%$ 

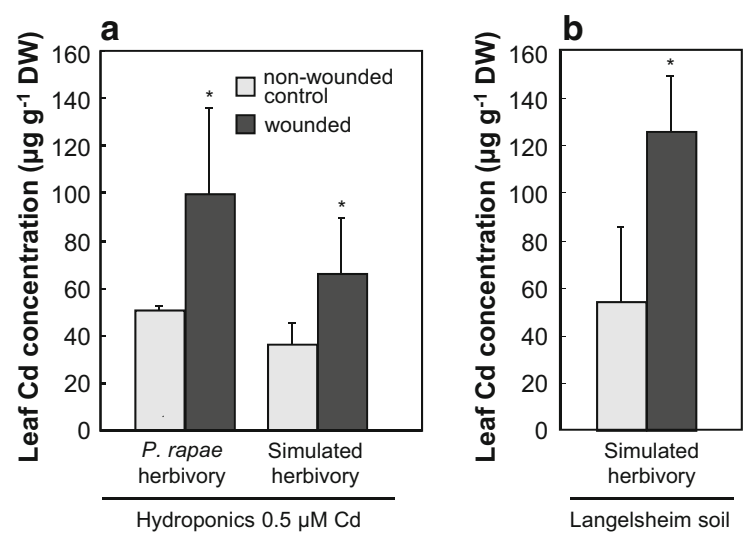

Fig. 1 Cadmium hyperaccumulation in Arabidopsis halleri is induced by herbivory and mechanical leaf wounding. a Leaf Cd concentrations were determined $72 \mathrm{~h}$ after wounding of $A$. halleri by herbivory through larvae of Pieris rapae or by mechanical wounding simulating herbivory. Plants were cultivated hydroponically. b Leaf Cd concentrations were determined upon mechanical wounding simulating herbivory in $A$. halleri cultivated on its native heavy metal-contaminated soil. Wounding was carried out four times consecutively at 72-h intervals, each time removing a total of approximately $50 \%$ of the area of one single leaf in between secondary veins on both sides of the mid-rib, with harvest of entire shoots $72 \mathrm{~h}$ after the last wounding event (color-coding of bars as in 1a). Shown data are arithmetic mean $\pm \mathrm{SD}$ of $n=3$ to 5 replicate plants from one experiment representative of two to three independent experiments. Asterisks indicate significant differences $(P<0.05)$ between wounded and non-wounded plants (Mann-Whitney U test). $D W$ dry biomass

of one leaf blade from Cd-supplemented A. halleri plants using a razor blade resulted in a comparable increase in leaf $\mathrm{Cd}$ concentrations $(P=0.007)$ (Fig. 1a). This confirmed that A. halleri responds to leaf wounding by increasing the accumulation of $\mathrm{Cd}$ in leaves. We also determined $\mathrm{Cd}$ accumulation in $A$. halleri plants grown on a metal-contaminated soil collected at the site of origin of the A. halleri population (Langelsheim, Germany). Compared to non-wounded plants grown on this Cd-contaminated soil, leaves of mechanically wounded plants contained higher $\mathrm{Cd}$ concentrations (Fig. 1b), with the average concentration exceeding the threshold concentration of $100 \mu \mathrm{g} \mathrm{g}^{-1} \mathrm{Cd}$ in leaf dry biomass, which is used to identify Cd hyperaccumulators in the field (Baker and Brooks 1989).

From A. halleri cultivated in a Cd-supplemented hydroponic medium (see Fig. 1a above), larvae of Pieris rapae ate $49.0 \pm 24.0 \%$ (arithmetic mean $\pm \mathrm{SD}$; $P=0.032$ ) less leaf biomass than from $A$. halleri

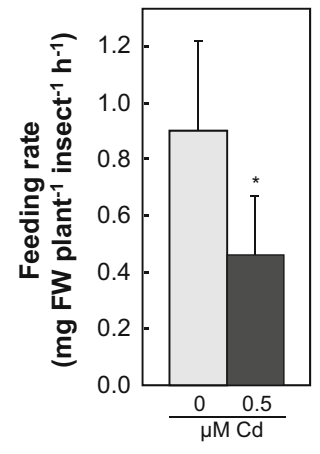

Fig. 2 Insect herbivory is decreased when Cd is available for accumulation by Arabidopsis halleri. a The rate of consumption of A. halleri leaf biomass by larvae of Pieris rapae was quantified 5 days after supplementation of hydroponic solution with no or $0.5 \mu \mathrm{M} \mathrm{CdCl}_{2}$. Shown data are arithmetic mean \pm SD of $n=3$ to 5 replicate plants from one experiment representative of two to three independent experiments. Asterisks indicate significant differences $(P<0.05)$ between wounded and non-wounded plants (Mann-Whitney U test). $F W$ fresh biomass

cultivated without added cadmium (Fig. 2). 5 days later, the larvae fed on $\mathrm{Cd}$-supplemented plants retained $3.26 \pm 0.37$ fold higher $\mathrm{Cd}$ concentrations (arithmetic mean $\pm \mathrm{SD} ; \quad P=0.029 ; \quad 2.15 \pm 0.22$ and $0.66 \pm 0.06 \mu \mathrm{g} \mathrm{Cd} \mathrm{g}^{-1}$ dry biomass, respectively; data not shown) than larvae fed on plants grown in a medium without added $\mathrm{Cd}$. This demonstrated that $\mathrm{Cd}$ accumulation in A. halleri can effectively deter insect herbivory.

Transpiration rates did not increase in response to wounding (data not shown). Therefore, woundinginduced $\mathrm{Cd}$ hyperaccumulation in A. halleri was hypothesized to involve increased $\mathrm{Cd}$ flux into the xylem of roots for transport into leaves via the transpiration stream. To investigate the systemic transcriptional response of roots to the wounding of leaves, we conducted comparative transcript profiling in roots of A. halleri and A. thaliana using microarrays harboring 25,000 gene-specific tags for the $A$. thaliana genome. Out of a total of 21,483 genes, for which expression signals were detected in A. halleri, the expression of 153 genes was more than 1.5-fold up- or downregulated in response to wounding $(P<0.05$; 44 up, 109 down; Supplementary Table 1). In $A$. thaliana, the expression of 228 genes out of a total of 21,489 expressed genes changed in response to wounding $(P<0.05 ; 44$ up, 184 down; Supplementary Table 2). The classification of wounding-responsive genes of $A$. halleri according to functional annotations (Usadel et al. 2005) and published responses (Colangelo 
Fig. 3 Comparison of systemic transcriptional responses of roots to simulated herbivory in $A$. halleri and A. thaliana. a Enrichment analysis. For each functional/regulatory class, bars represent the proportion of woundingresponsive genes contained therein, and the proportion of all genes detected on the CATMA arrays as a reference $(* * * P<0.001$; Fisher's exact test).

b Average $\log _{2}$ (fold changes) in root transcript levels of wounded versus non-wounded plants for selected iron deficiency response genes. Systemic wounding-induced changes in gene expression were determined in roots $5 \mathrm{~h}$ after leaf wounding relative to non-wounded controls using CATMA microarrays, and averaged from four independent experiments. Oxylipin family compounds: OPDA (12-oxo phytodienoic acid), MJ (methyl jasmonate)

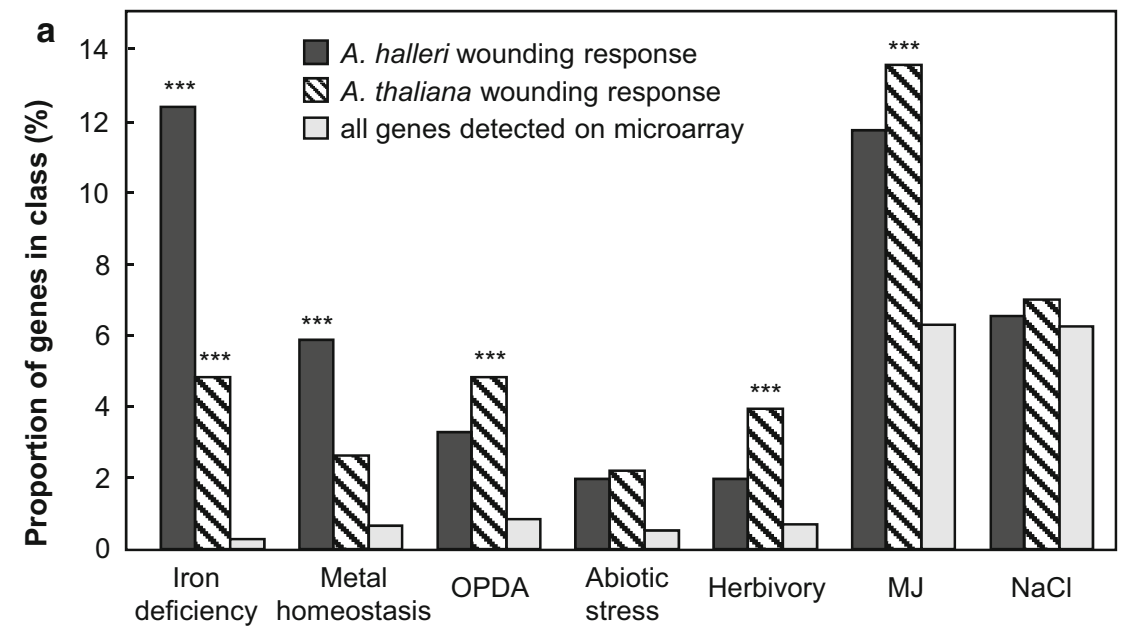

Regulatory or functional class

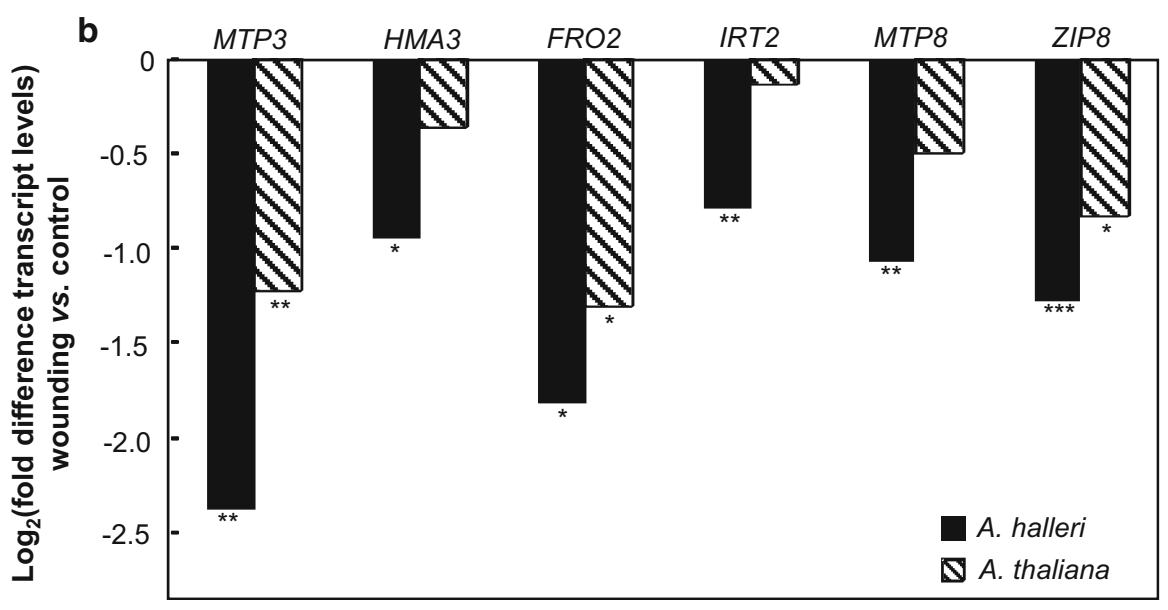

and Guerinot 2004; Gong et al. 2005; Kilian et al. 2007; Nemhauser et al. 2006; Reymond et al. 2004; Taki et al. 2005) indicated that Fe-deficiency response genes (Colangelo and Guerinot 2004), metal homeostasis genes (Talke et al. 2006) and 12-oxo-phytodienoic acid (OPDA)-responsive genes (Taki et al. 2005) were 44-, 8.3- and 3.9-fold overrepresented, respectively, compared to the representation of these classes of genes among all expressed genes (Fig. 3a). By comparison, among systemically wounding-responsive genes of A. thaliana, there was no statistically significant overrepresentation of metal homeostasis genes in general, but iron deficiency response genes were 17-fold and OPDA-responsive genes were 5.8-fold overrepresented, respectively.

Metal Tolerance Protein3 (MTP3), which encodes a vacuolar membrane $\mathrm{Zn}^{2+} / \mathrm{H}^{+}$antiporter in $A$. thaliana (Arrivault et al. 2006), was the most strongly regulated transcript in roots in response to leaf wounding in A. halleri, with a decrease by $81 \%$ compared to non-wounded controls (Fig. 3b; see also Supplementary Table 1). The response of MTP3 transcript levels was similar, but quantitatively less pronounced, in A. thaliana, with a decrease by $57 \%$ compared to non-wounded controls. Upon wounding of A. halleri, a decrease in transcript levels was also observed for Heavy Metal ATPase3 (HMA3), which encodes a putative vacuolar membrane $\mathrm{Zn}^{2+} / \mathrm{Cd}^{2+}$ / $\mathrm{Pb}^{2+}$ pump (Gravot et al. 2004; Morel et al. 2009). Both MTP3 and HMA3 are part of the Fe-deficiency Induced Transcription Factorl (FIT1) regulon of A. thaliana (Colangelo and Guerinot 2004), i.e. their transcription is enhanced in roots under Fe deficiency dependent on the transcription factor FIT1. Indeed, 
transcript levels of Ferric Reductase Oxidase2 (FRO2), Iron-Regulated Transporter2 (IRT2) and Metal Tolerance Protein8 (MTP8), all of which belong to the FIT1 regulon, were also decreased in roots of wounded plants, again pronouncedly in $A$. halleri and not or only moderately in A. thaliana (Fig. 3b), among others (Supplementary Tables 1 and 2). The systemic wounding response of metal homeostasis genes neither encompassed the entire FITI regulon, nor was it restricted to the FITI regulon alone, including also, for example, the Zinc-regulated transporter, Iron-regulated transporter Protein8 (ZIP8), which does not belong to the FIT1 regulon (Fig. 3b). Using qPCR, the microarray data were confirmed for all these genes (Figure S1). Taken together, these results show that leaf wounding elicits a systemic transcriptional response in roots, in which metal homeostasis and Fe deficiency response gene transcript levels are suppressed more strongly in $A$. halleri than in A. thaliana.

\section{Discussion}

To a considerable degree, research on metal hyperaccumulation was based on the implicit assumption that metal hyperaccumulation or hypertolerance mechanisms must be inducible by exposure of a hyperaccumulator plant to elevated concentrations of the cognate metal. By contrast, it came as a surprise that all candidate genes-including HMA4, Metal Tolerance Proteinl (MTP1) and Nicotianamine Synthase2 (NAS2) that are presently known to be of central functional importance-are constitutively highly expressed in A. halleri by comparison to closely related non-accumulators (Becher et al. 2004; Weber et al. 2004). A subgroup of highly expressed candidate genes of $A$. halleri consists of $\mathrm{Zn}$ deficiency response genes (Talke et al. 2006). Their transcript levels are generally high in A. halleri as a consequence of HMA4-mediated $\mathrm{Zn}$ depletion in roots (Hanikenne et al. 2008), but they also retain their responsiveness to $\mathrm{Zn}$-mediated repression of transcript levels known for their homologues in A. thaliana. In agreement with this, root-shoot $\mathrm{Zn}$ partitioning in $A$. halleri depends on external $\mathrm{Zn}$ supply (Talke et al. 2006).

As shown here, both herbivory and mechanical leaf wounding enhanced leaf $\mathrm{Cd}$ accumulation in A. halleri
(Fig. 1). This must involve altered activities of processes in roots, and thus systemic signaling. Wounding-triggered leaf-to-leaf systemic signaling was recently shown to involve the movement of electrical surface potential changes dependent on ionotropic glutamate receptor-related plant proteins and to occur very fast (Mousavi et al. 2013). It is surprising that in A. halleri, wounding-activated processes act preferentially or even specifically to enhance shoot $\mathrm{Cd}$ accumulation. $\mathrm{Cd}^{2+}$ is not an essential nutrient in higher plants so that it generally accumulates in plants along pathways of chemically related nutrient metal cations such as $\mathrm{Fe}^{2+}$ or $\mathrm{Zn}^{2+}$ (Clemens et al. 2013). Our data suggested a comparably large variation of leaf $\mathrm{Cd}$ accumulation (see Fig. 1). We attribute this to the difficulty of both administering reproducible degrees of wounding and preventing accidental wounding in control plants. Moreover, both insect herbivory and pathogens can trigger overlapping signaling pathways, for example those involving the oxylipin family of plant hormones including jasmonates. A. halleri is particularly prone to pathogen and insect pests, and thus it is technically difficult to entirely exclude the presence of all biotic stress in experiments (Maja Schellenberg, Ina Talke, Ricardo Stein, Enrico Martinoia and Ute Krämer, unpublished observations). We expect that, in addition to leaf wounding, other biotic factors also act to enhance leaf $\mathrm{Cd}$ accumulation. For example, it has been reported that the natural root microbiome of $A$. halleri had a modestly enhancing effect on leaf $\mathrm{Cd}$ accumulation (Farinati et al. 2009; Muehe et al. 2015), but also this system remains challenging to control (Farinati et al. 2011). Rich microbiomes are known to colonize both above- and below-ground organs of plants, adding to the complexity of these experiments (Bulgarelli et al. 2012; Horton et al. 2014; Lundberg et al. 2012).

Leaf wounding is known to activate oxylipin-based signaling (Nemhauser et al. 2006; Reymond et al. 2004; Taki et al. 2005). This was observed here in the systemic transcriptional response of roots of $A$. thaliana and-to a lesser degree-A. halleri, with the activation of transcriptional methyl jasmonate, 12-oxophytodienoic acid (OPDA) and herbivory responses (Fig. 3a). Especially among the responses of $A$. halleri, we observed a striking overrepresentation of Fe deficiency responses and metal homeostasis genes. Upon closer investigation, this response 
consisted to a large extent of the transcriptional repression of Fe deficiency response genes, in particular genes of the FIT1 regulon (Supplementary Tables 1 and 2). Future studies will address whether or not this transcriptional response contributes to the wounding-induced leaf $\mathrm{Cd}$ accumulation response in A. halleri.

In A. thaliana, there was no increase in leaf $\mathrm{Cd}$ accumulation in response to wounding (data not shown). In agreement with this, despite a strong activation of herbivory responses in A. thaliana (see Fig. 3a), the transcriptional repression of Fe deficiency response genes was quantitatively far less pronounced in A. thaliana, with fewer genes detected to respond in our microarray analysis. Our data are consistent with a report that jasmonate treatment of $A$. thaliana resulted in decreased transcript levels of $\mathrm{Fe}$ deficiency response genes (Maurer et al. 2011).

Our transcript profiling identified some candidate genes for contributions to wounding-enhanced leaf $\mathrm{Cd}$ accumulation in A. halleri. MTP3 was the most strongly repressed transcript in response to leaf wounding. In $A$. thaliana, transcription of the FIT1 target MTP3 is activated when root $\mathrm{Zn}^{2+}$ uptake rates are enhanced under $\mathrm{Fe}$ deficiency and excess $\mathrm{Zn}$. Under these conditions, the vacuolar-membrane localized MTP3 protein acts to sequester $\mathrm{Zn}^{2+}$ in vacuoles of root epidermal and cortex cells, thus decreasing shoot $\mathrm{Zn}$ accumulation (Arrivault et al. 2006). A decrease in MTP3 expression would thus be predicted to enhance root-to-shoot $\mathrm{Zn}$ transport. A. thaliana MTP3 was found not to transport $\mathrm{Cd}^{2+}$, but the specificity of $A$. halleri MTP3 remains to be investigated. Another interesting candidate gene is the FIT1 target HMA3. Similar to MTP3, this $\mathrm{P}_{1 \mathrm{~B}}$-type ATPase can also mediate the vacuolar sequestration of $\mathrm{Zn}^{2+}$, as well as of $\mathrm{Cd}^{2+}$ and $\mathrm{Pb}^{2+}$, in the root (Morel et al. 2009). The transcriptional repression of $H M A 3$ in roots of wounded $A$. halleri plants could thus decrease $\mathrm{Cd}$ immobilization inside roots and enhance the translocation of $\mathrm{Cd}$ into the shoots.

In A. thaliana, the systemic transcriptional repression of other FIT1 targets, for example FRO2 (Fig. 3b) and IRT1 (Supplementary Fig. 1), in the root is predicted to decrease the reduction of $\mathrm{Fe}^{\mathrm{III}}$ chelates to $\mathrm{Fe}^{2+}$ and root uptake rates of $\mathrm{Fe}^{2+}$. In addition, root uptake of $\mathrm{Cd}^{2+}$ is expected to decrease because this heavy metal cation is primarily taken up through the high-affinity $\mathrm{Fe}^{2+}$ uptake system IRT1 in A. thaliana. The same effect is predicted in $A$. halleri unless this species possesses another, yet unidentified, root uptake system for $\mathrm{Cd}^{2+}$. If, indeed, $A$. halleri possessed such a root uptake system for $\mathrm{Cd}^{2+}$, the decreased expression of FIT1 regulon genes upon leaf wounding would have entirely different consequences for overall metal homeostasis: For example, the decreased expression of $F R O 2$, in particular, would be expected to lower the concentration of extracellular $\mathrm{Fe}^{2+}$ competing with $\mathrm{Cd}^{2+}$ for uptake into root cells and to enhance plant $\mathrm{Cd}$ accumulation, and the latter was observed here in A. halleri. Future work will address each of these hypotheses.

In conclusion, our data suggest that in the metal hyperaccumulator $A$. halleri wounding induces signals that act systemically in the root to trigger enhanced leaf $\mathrm{Cd}$ accumulation, which in turn functions as a defense against attack by herbivores (Fig. 2), and possibly also pathogens (Boyd 2007). The existence of inducible metal hyperaccumulation in A. halleri provides strong circumstantial support for the elemental defense hypothesis (Boyd 2007). Furthermore, this observation requires an analysis of the underlying molecular mechanisms, and it will guide the design of future experiments addressing metal hyperaccumulation.

Acknowledgments We thank Prof. Y. Lee, Univ. Pohang, S. Korea for continuous support and discussions, and Dr. D. Wanke and Prof. K. Harter, University of Tuebingen, Germany, for sharing unpublished data. This work was supported by the EU project PHIME (FOOD-CT-2006016253, U.K., E.M.), by the Korean Ministry of Sciences (GRL program Grant No. 4.0001795.01 to Y.L., E.M.), by the German Research Foundation (Heisenberg fellowship $\mathrm{Kr}$ 1967/4-1 and Research Priority Program 1529 ADAPTOMICS Kr1967/10-1, U.K.).

Open Access This article is distributed under the terms of the Creative Commons Attribution License which permits any use, distribution, and reproduction in any medium, provided the original author(s) and the source are credited.

\section{References}

Arrivault S, Senger T, Krämer U (2006) The Arabidopsis metal tolerance protein AtMTP3 maintains metal homeostasis by mediating $\mathrm{Zn}$ exclusion from the shoot under Fe deficiency and Zn oversupply. Plant J 46:861-879

Baker AJM, Brooks RR (1989) Terrestrial higher plants which hyperaccumulate metallic elements-a review of their distribution, ecology and phytochemistry. Biorecovery 1:81-126

Becher M, Talke IN, Krall L, Krämer U (2004) Cross-species microarray transcript profiling reveals high constitutive 
expression of metal homeostasis genes in shoots of the zinc hyperaccumulator Arabidopsis halleri. Plant J 37:251-268

Bovet L et al (2003) Transcript level of AtMRPs after cadmium treatment: induction of AtMRP3. Plant, Cell Environ 26:371-381

Boyd RS (2007) The defense hypothesis of elemental hyperaccumulation: status, challenges and new directions. Plant Soil 293:153-176

Boyd RS, Martens SN (1992) The raison d'être for metal hyperaccumulation in plants. In: Baker AJM, Proctor J, Reeves RD (eds) The vegetation of ultramafic (serpentine) soils. Intercept, Andover, pp 279-289

Bulgarelli D et al (2012) Revealing structure and assembly cues for Arabidopsis root-inhabiting bacterial microbiota. Nature 488:91-95. doi:10.1038/nature11336

Clemens S, Aarts MG, Thomine S, Verbruggen N (2013) Plant science: the key to preventing slow cadmium poisoning. Trends Plant Sci 18:92-99. doi:10.1016/j.tplants.2012.08. 003

Colangelo EP, Guerinot ML (2004) The essential basic helixloop-helix protein FIT1 is required for the iron deficiency response. Plant Cell 16:3400-3412

Dahmani-Muller H, Van Oort F, Gelie B, Balabane M (2000) Strategies of heavy metal uptake by three plant species growing near a metal smelter. Environ Pollut 109:231-238

Farinati S et al (2009) Proteomic analysis of Arabidopsis halleri shoots in response to the heavy metals cadmium and zinc and rhizosphere microorganisms. Proteomics 9:4837-4850. doi:10.1002/pmic.200900036

Farinati S, DalCrso G, Panigati M, Furini A (2011) Interaction between selected bacterial strains and Arabidopsis halleri modulates shoot proteome and cadmium and zinc accumulation. J Exp Bot 62:3433-3447. doi:10.1093/jxb/ err015

Gong Q, Li P, Ma S, Indu Rupassara S, Bohnert HJ (2005) Salinity stress adaptation competence in the extremophile Thellungiella halophila in comparison with its relative Arabidopsis thaliana. Plant J 44:826-839

Gravot A, Lieutaud A, Verret F, Auroy P, Vavasseur A, Richaud $P$ (2004) AtHMA3, a plant P(1B)-ATPase, functions as a $\mathrm{Cd} / \mathrm{Pb}$ transporter in yeast. FEBS Lett 561:22-28

Hanikenne $\mathrm{M}$ et al (2008) Evolution of metal hyperaccumulation required cis-regulatory changes and triplication of HMA4. Nature 453:391-395

Hilson P et al (2004) Versatile gene-specific sequence tags for Arabidopsis functional genomics: transcript profiling and reverse genetics applications. Genome Res 14:2176-2189

Horton MW et al (2014) Genome-wide association study of Arabidopsis thaliana leaf microbial community Nat Commun 5:5320. doi:10.1038/ncomms6320

Kazemi-Dinan A, Thomaschky S, Stein RJ, Krämer U, Müller C (2014) Zinc and cadmium hyperaccumulation act as deterrents towards specialist herbivores and impede the performance of a generalist herbivore. New Phytol 202:628-639. doi:10.1111/nph.12663

Kilian J et al (2007) The AtGenExpress global stress expression data set: protocols, evaluation and model data analysis of UV-B light, drought and cold stress responses. Plant $\mathbf{J}$ 50:347-363

Krämer U (2010) Metal hyperaccumulation in plants. Annu Rev Plant Biol 61:517-534
Lundberg DS et al (2012) Defining the core Arabidopsis thaliana root microbiome. Nature 488:86-90. doi:10.1038/ nature 11237

Massonneau A, Langlade N, Leon S, Smutny J, Vogt E, Neumann G, Martinoia E (2001) Metabolic changes associated with cluster root development in white lupin (Lupinus albus L.): relationship between organic acid excretion, sucrose metabolism and energy status. Planta 213:534-542

Maurer F, Muller S, Bauer P (2011) Suppression of Fe deficiency gene expression by jasmonate. Plant Physiol Biochem 49:530-536. doi:10.1016/j.plaphy.2011.01.025

Mithofer A, Boland W (2012) Plant defense against herbivores: chemical aspects. Annu Rev Plant Biol 63:431-450. doi:10.1146/annurev-arplant-042110-103854

Morel M, Crouzet J, Gravot A, Auroy P, Leonhardt N, Vavasseur A, Richaud P (2009) AtHMA3, a P1B-ATPase Allowing $\mathrm{Cd} / \mathrm{Zn} / \mathrm{Co} / \mathrm{Pb}$ Vacuolar Storage in Arabidopsis. Plant Physiol 149:894-904

Mousavi SA, Chauvin A, Pascaud F, Kellenberger S, Farmer EE (2013) GLUTAMATE RECEPTOR-LIKE genes mediate leaf-to-leaf wound signalling. Nature 500:422-426. doi:10. 1038/nature 12478

Muehe EM, Weigold P, Adaktylou IJ, Planer-Friedrich B, Krämer U, Kappler A, Behrens S (2015) Rhizosphere microbial community composition affects cadmium and zinc uptake of the metal-hyperaccumulating plant Arabidopsis halleri. Appl Environ Microbiol. [Epub ahead of print]

Nemhauser JL, Hong F, Chory J (2006) Different plant hormones regulate similar processes through largely nonoverlapping transcriptional responses. Cell 126:467-475

Reymond P, Bodenhausen N, Van Poecke RM, Krishnamurthy V, Dicke M, Farmer EE (2004) A conserved transcript pattern in response to a specialist and a generalist herbivore Plant Cell 16:3132-3147

Taki $\mathrm{N}$ et al (2005) 12-oxo-phytodienoic acid triggers expression of a distinct set of genes and plays a role in woundinduced gene expression in Arabidopsis. Plant Physiol 139:1268-1283

Talke IN, Hanikenne M, Krämer U (2006) Zinc-dependent global transcriptional control, transcriptional deregulation, and higher gene copy number for genes in metal homeostasis of the hyperaccumulator Arabidopsis halleri. Plant Physiol 142:148-167

Usadel B et al (2005) Extension of the visualization tool MapMan to allow statistical analysis of arrays, display of corresponding genes, and comparison with known responses. Plant Physiol 138:1195-1204

Verbruggen N, Hermans C, Schat H (2009) Molecular mechanisms of metal hyperaccumulation in plants. New Phytol 181:759-776. doi:10.1111/j.1469-8137.2008. 02748.x

Weber M, Harada E, Vess C, Roepenack-Lahaye EV, Clemens S (2004) Comparative microarray analysis of Arabidopsis thaliana and Arabidopsis halleri roots identifies nicotianamine synthase, a ZIP transporter and other genes as potential metal hyperaccumulation factors. Plant $\mathrm{J}$ 37:269-281

Yang YH, Dudoit S, Luu P, Lin DM, Peng V, Ngai J, Speed TP (2002) Normalization for cDNA microarray data: a robust composite method addressing single and multiple slide systematic variation. Nucleic Acids Res 30:e15 